\title{
CARPAL TUNNEL SYNDROME: BETWEEN CONSERVATIVE TREATMENT AND THOSE TREATED SURGICALLY AFTER FAILED CONSERVATIVE TREATMENT
}

\author{
Omar BMI \\ Department of Orthopaedic Surgery, University of Malaya Medical Centre, 50603 Kuala Lumpur, Malaysia
}

\begin{abstract}
A retrospective study of $\mathbf{1 0 2}$ hands with carpal tunnel syndrome which were treated conservatively initially. Patients who were successfully treated with this method were then compared with those who had failed with this method and had to be treated with surgical decompression. This study found that it took a mean period of about 5.1 months of conservative treatment before deciding on surgery. Generally, the study shows a predominant involvement of the right hand and the female sex as full-time homemakers. Those who finally needed surgery had a longer duration of symptoms prior to consultation. Surgery brought a faster relief from both pain and numbness. It is recommended that conservative treatment be abandoned after a trial period of at least three to five months in order to encourage a speedier recovery. (JUMMEC 2003-2005; 8: 50-55)
\end{abstract}

KEYWORDS: Carpal tunnel syndrome, phalen, pinel, median nerve motor latency, median nerve sensory latency

\section{Introduction}

The carpal tunnel is narrowest 2.0 to $2.5 \mathrm{~cm}$ distal to its proximal margin (mean of $20 \mathrm{~cm}$ ), widening both proximally and distally (mean of $2.5 \mathrm{~cm}$ ) $(\mathrm{I}-2)$, which corresponds to the recognized greatest morphologic changes in cases of carpal tunnel syndrome (CTS) (3).

The volume of the carpal tunnel is not static and significant changes occur with flexion and extension as shown by the MRI. Some studies have shown that patients afflicted with CTS have smaller carpal canals than the normal population. This suggests that certain individuals have a hereditary predisposition on the development of CTS on the basis of carpal size.

Acute CTS is a syndrome in which there is a rapid rise and sustained increase in interstitial pressure within the carpal tunnel. This may result from haemorrhage, injection injuries, burns and pyogenic infection. Others have suggested that the primary pathophysiologic mechanism underlying the nerve conduction block in acute CTS is related to acute intracompartmental and intraneural ischaemia (4-5).

External compression of the peripheral nerve by 20 to $30 \mathrm{mmHg}$ results in a decreased epineural venous blood flow and at levels of 60 to $80 \mathrm{mmHg}$, there is an immediate complete cessation of intraneural blood flow (6).

Chronic CTS is a compressive neuropathy in which there is an insidious rise in the carpal tunnel interstitial pressure of moderate degree (7). It ranges from early stage where there is no gross morphologic changes in the median nerve to the intermediate stage of numbness and paraesthesia and median nerve demonstrates epineural and intrafascicular oedema and to the advanced stage of fibrillation potentials and with endoneural oedema, intraneural fibrosis, partial demyelination and axonal degeneration (6). The changes in the intermediate stage are reversible with decompression but in the advanced stage it is irreversible.

The increased pressure also has a direct mechanical effect on axonal transport. Experimental data suggests that persistent compression at $20 \mathrm{mmHg}$ results in the reduction in orthograde fast axonal transport with progressive dysfunction almost complete with pressure above $200 \mathrm{mmHg}(8)$.

Correspondence:

Dr Omar Md Isa

Department of Orthopaedic Surgery

University of Malaya Medical Centre

50603 Kuala Lumpur

Malaysia 
The sequelae of local ischaemia is destruction and replacement of the epineurium and endoneurium with dense fibrous tissue. This causes distal nerve fibre degeneration resulting in abnormal impulse generation and transmission, conduction delay or complete nerve block. These manifest as pain, paraesthesia and numbness (9).

\section{Methods}

This is a retrospective study involving 120 patients with the diagnosis of CTS seen at the Hand and Microsurgery Unit, Kuala Lumpur General Hospital from January 1993 to December 1996 with a followup period was fifteen months. The source of information was the patients' medical records.

A criteria for the diagnosis of the CTS in the study was determined by the Unit such as:

I. symptoms of pain, tingling sensation or numbness either at night, during activities only or at all times, clumsiness of the hand and sensation of heaviness in the affected hand or hands, and

2. either positive Phalen's test or positive Tinel's sign.

From the number, 24 patients were excluded due to incomplete data and another 14 due to associated medical conditions like cervical spondylosis, chronic renal failure, diabetes, rheumatoid arthritis and history of wrist trauma. From the remaining 82 patients, there were 102 hands taken into study. Twenty patients had bilateral involvement but each hand was treated differently and thus regarded as a separate hand.

\section{Demographic data}

Data taken included age, occupation, dominant hand, the side of hand involved, duration of symptoms and the date of the first visit.

Those chosen were the ones whose symptoms as defined by the criteria above.

\section{Clinical examination}

The areas of altered sensation or paraesthesia were determined using a pinwheel. The wheel was passed in turn from the digits into the palm, moving from the area of absolute innervation by the median nerve into that supplied by the palmar cutaneous nerve. In CTS, a change will occur at some point between the two areas. Repeated comparison was made with the ulnarinnervated digits and with those on the other hand, and particular attention was paid to the palmar triangle whose sensation was derived from the palmar cutaneous nerve.
The strength of the abductor pollicis brevis muscle was graded according to the Medical Research Council (MRC) scale and any thenar muscle wasting noted. The Phalen's test was performed either actively by the patient or assisted and considered positive when the abnormal sensation was felt within 60 seconds. If this was negative, a reversed Phalen's test was performed.

\section{Investigation}

Nerve conduction studies of both the distal sensory and motor latencies of only the median nerve were taken into account. There were then categorized into no response, normal, mild, moderate and severe responses according to the criteria set by Choi and Ahn (10).

\section{Treatment}

All patients underwent conservative treatment with splintage, oral tablets of vitamin B6 with or without analgesics depending on the circumstances. Those who were successfully treated with this method were classified under group A. There were $5 \mathrm{I}$ hands in this group.

During the course of conservative treatment, about 24 patients were given steroid injection into the carpal tunnel, whereby seven of them finally ended with surgical treatment. However, their numbers were quite small to influence the study significantly.

The criteria for surgical treatment were:

- worsening of symptoms,

- poor compliance, and

- abductor pollicis brevis muscle power of grade three or less.

Seven patients gave persistent symptoms and two gave worsening of symptoms as reasons to discontinue conservative treatment.

Those patients who finally had to undergo surgery were categorized as Group B.There were $5 \mathrm{I}$ hands in this group, too.

Surgical decompression was performed either via endoscopic (four hands) or open surgical technique. Endoscopic surgeries were abandoned later due to a high complication rate.

\section{Result of treatment}

The two factors taken into account that indicated success of treatment were resolution from pain and numbness. 


\section{Results}

Their mean age was from 43.5 years (range of 23-65 years). Out of 82 patients, 7 I (82.6\%) were females.

There were $76(92.6 \%)$ right hand dominant patients. There were $66(80.5 \%)$ right hands involved out of 102 hands. 20 (24.2\%) patients had bilateral involvement.

There were 42 (5I.2\%) patients in the sedentary jobs who were mainly office workers. There were 30 (36.5\%) patients who were considered as full-time homemakers and finally 10 (12.3\%) patients who were labourers.

For the Group A patients (those who were successful with conservative treatment), the mean duration of symptoms prior to consultation was 16.1 months (range of 0.3-96 months). For the Group B patients (those who finally needed surgery) the mean duration of symptoms prior to consultation was 29.1 months (range of 0.3-120 months). Using a two independent t-test, there was a significance difference in the duration of symptoms prior to consultation between the two groups $(p<0.001)$.

The distribution of paraesthesia on various regions of the hand showed a preponderance towards the area of the radial three and a half digits.

There were three hands from each group that demonstrated involvement of more than one region (Table I).

The result of the abductor pollicis brevis muscle power testing is shown in Table 2. It shows that the distribution is almost equal for both groups.

In Group B, there were seven hands with thenar muscle wasting compared to six hands in Group A.

The Phalen's test has a higher sensitivity compared to the Tinel's sign (Table 3).

Except for one, all patients with bilateral involvement reported that the duration of symptoms occurred simultaneously for both hands.

With the nerve conduction studies, Group A showed a slightly higher number of hands with severe grade with the median motor latency test but for the sensory latency test, the number of hands with no response and with severe grade were almost equal for both groups (Table 4).
Table I. A table on the distribution of altered sensation in the hands according to three regions. The extra three hands in each group had paraesthesiae of more than one region.

\begin{tabular}{|c|c|c|}
\hline & $\begin{array}{c}\text { Group } A \\
n=51\end{array}$ & $\underset{\substack{n=51 \\
\text { Group } B}}{ }$ \\
\hline Paraesthesiae of whole palm & II & 15 \\
\hline $\begin{array}{l}\text { Paraesthesiae of the radial } \\
\text { three and a half digits }\end{array}$ & 34 & 30 \\
\hline Paraesthesiae of all the digits & 9 & 9 \\
\hline Total number of hands & 54 & 54 \\
\hline
\end{tabular}

Table 2. A table of the abductor pollicis brevis motor power

\begin{tabular}{ccc}
\hline & $\begin{array}{c}\text { Group A } \\
n=5 \text { I }\end{array}$ & $\begin{array}{c}\text { Group B } \\
n=5 \text { I }\end{array}$ \\
\hline Grade 3 & 1 & 1 \\
Grade 4 & 15 & 23 \\
Grade 5 & 35 & 27 \\
\hline
\end{tabular}

Table 3. A table on the results of the Phalen's test and Tinel's sign

\begin{tabular}{llcc}
\hline & & $\begin{array}{c}\text { Group A } \\
n=5 \text { I }\end{array}$ & $\begin{array}{c}\text { Group B } \\
n=5 \text { I }\end{array}$ \\
\hline Phalen's test & positive & 47 & 46 \\
& negative & 4 & 5 \\
Tinel's sign & positive & 26 & 26 \\
& negative & 25 & 25 \\
\hline
\end{tabular}

The mean duration period of failed conservative treatment before proceeding to surgery in Group B was 5.1 months (range of 0.3-15 months).

\section{Post treatment period of resolution from pain}

For Group A patients, the mean duration time was 4.8 months (range of 0.3-13 months). For the Group B patients, the mean duration time was 1.8 months (range of 0.3-6.5 months) after surgery.

\section{Post treatment period of resolution from numbness}

For the Group A, the mean duration time was 4.8 months (range of 0.3-13 months) versus Group B patients, who took a mean period of 2.5 months (range of 0.2-6.5 months) after surgery. 
Table 4. A table on the results of the median nerve latency test

\begin{tabular}{|c|c|c|c|c|}
\hline & & msec & $\begin{array}{c}\text { Group } A \\
n=51\end{array}$ & $\begin{array}{c}\text { Group B } \\
n=51\end{array}$ \\
\hline \multirow[t]{5}{*}{ Median motor nerve latency } & no response & 0 & 4 & II \\
\hline & normal & $4.0<$ & 1 & 0 \\
\hline & mild & $4.0-4.9$ & 6 & 5 \\
\hline & moderate & $5.0-7.0$ & 8 & 6 \\
\hline & severe & $>7.0$ & 32 & 29 \\
\hline \multirow[t]{5}{*}{ Median sensory nerve latency } & no response & 0 & 15 & 22 \\
\hline & normal & $3.0<$ & 3 & 2 \\
\hline & mild & $3.0-3.9$ & 10 & 5 \\
\hline & moderate & $4.0-6.0$ & 4 & 1 \\
\hline & severe & $>6.0$ & 19 & 21 \\
\hline
\end{tabular}

One hand from the Group B did not gain any relief from pain and numbness and was thus discounted.

Using the t-test, there was significant difference statistically in the period of resolution from both pain $(p<0.00 \mathrm{I})$ and numbness $(p<0.00 \mathrm{I})$ between the two groups.

\section{Discussion}

It is still controversial whether work-related hand or wrist overuse is a risk factor for developing carpal tunnel syndrome. Phalen and co-workers (I I) maintained that it was not an occupational disease. They stated that, whereas hand overuse might provoke symptoms, it was unlikely that occupation alone could be considered a causative factor or the condition would be encountered more frequently.

It has been reported that there was no consistent association between the prevalence of carpal tunnel syndrome and the type and level of occupational hand activity, duration of employment or bilateral versus unilateral activity (I2).

It has also been shown that the volume of the carpal tunnel is relatively smaller in women than in men and this difference may be a predisposing factor for the development of carpal tunnel syndrome and thus a higher prevalence amongst women (13).

Others have reported that the mean duration of symptoms was 24 months for both the left and right hands (14). This almost coincides with this study whereby the duration of symptoms was 16.1 months for those successful with conservative treatment and 29.I months for those who finally needed surgery. There was so much nerve destruction in those hands that had to undergo operative treatment probably due to the delay in seeking treatment.

Both the Phalen's and the Tinel's tests are quite unreliable in diagnosing carpal tunnel syndrome. The sensitivity of Phalen's test is estimated to range from $10 \%$ to $88 \%$ and of Tinel's sign from $26 \%$ to $79 \%$. The estimates of the specificity of Phalen's test ranges from $47 \%$ to $100 \%$ and of Tinel's sign from $45 \%$ to $100 \%$ (15).

In patients with prolonged distal motor and sensory latencies preoperatively, significant improvement in conduction times were seen after surgical decompression, correlating with relief of symptoms. It was suggested that the relief of symptoms after surgery is the result of a reduction in spontaneous activity generated by the compressed nerve fragment than from the recovery from conduction block (16). In severe cases, localized demyelination is the main cause of nerve conduction delay and in more severe cases there may also be loss of larger fibres. In order to reduce false negatives, the Choi and Ahn criteria were used rather than that of DeKrom et al (17) and Martinez (18) (who opined that motor latency of less than $4.0 \mathrm{msec}$ and sensory latency of less than $3.7 \mathrm{msec}$ be considered normal). The DeKrom and Martinez's have only a $40 \%$ to $50 \%$ diagnostic rate (17).

The nearly $10 \%$ incidence of false-negative electrodiagnostic tests result in most large studies of CTS, perhaps is the biggest pitfall. There are patients with obvious CTS but with normal test. If only a small number of medium or small-sized nerve fibres are blocked, there will be no measurable effect on the conduction speed or the size of action potential, but it is likely that such a situation could cause clinical symptoms. The paraesthesia in early and mild CTS are caused by ectopic excitation of impulses within the 
nerve by ischaemia or mechanical irritation even before any conduction block has developed.

Others have recommended a waiting period of six months after the initial diagnosis before performing surgery (19). In this study, surgery was performed after a median period of 12 weeks after the initial diagnosis. Those undergone conservative treatment needed a period of median 13 weeks before embarking on surgery.

It was also found that the mean time for the resolution of symptoms was between six and nine months (20), while in this study, the mean time for resolution from both pain and numbness was 4.8 and 1.8 months respectively. While for those treated surgically, the mean time for resolution from pain and numbness was 4.8 and 2.5 months respectively.

Surgery itself is not without complications. The endoscopic surgery gives the most complication in terms of recurrence and pillar pain. Probably that is the reason for it's abandonment six months later. Open surgery too, has it's share of complications predominantly pillar pain and scar tenderness.

There are several limitations in this study. Apart from a small sample, there is a lack of a third observer to eliminate the bias occurring between the examiner and the patient during the conduct of the physical examination. There is poor documentation of the nerve conduction study records as the majority only showed latency velocities without the amplitude. Bias may also occur in the period of resolution of symptoms as those hands which have undergone surgery might have gained some benefit from the initial conservative treatment.

There was also more emphasis on conservative treatment in the later period of the study. Given adequate time the symptoms may resolve by themselves. Public awareness, too played a role as the patients either came on their own or were referred.

\section{Conclusion}

The hands which failed with conservative treatment and later have to undergo surgery have a longer duration of symptoms before seeking treatment. Surgery offered a faster relief from pain and numbness. It would be unreasonable to deny surgery after failed non-surgical treatment for a period of five to six months.

\section{Acknowledgements}

This paper is a summary of a thesis of the same name submitted for the Masters of Orthopaedic Surgery for the academic year of 1999. I thank Dr. K. Pathmanaban, the Head of Department of the Hand and Reconstructive Unit of the Hospital Besar, Kuala Lumpur. Although he was not directly involved in the production of the thesis, he was helpful in allowing me access to his patients' data.

I also thank Dr. Noran Naqiah Mohd Khairi from the Department of Social and Preventive Medicine for helping me with the statistics.

\section{References}

I. Cobb TK, Dalley BK, Posteraro RH, et al. Anatomy of flexor retinaculum. J Hand Surg 1986; I IA:5 I2-5 I4.

2. Robbins $\mathrm{H}$. Anatomical study of the median nerve in the carpal tunnel and etiologies of the carpal tunnel syndrome. J Bone Joint Surg 1963; 45A:953-966.

3. Armstrong TJ, Castelli WA, Evans FG. Some histological changes in carpal tunnel contents and their biomechanical implications. J Occup Med 1984; 26:197-20I.

4. Gelberman RH, Szabo RM, Williamson RV, et al. Tissue pressure threshold for peripheral nerve viability. Clin Orthop 1983; 178:285-293.

5. Szabo RM, Gelberman RH,Williamson RV, et al. Effects of increased pressure on the tissue fluid pressure threshold of peripheral nerve. J Orthop Res 1983; I:I72-179.

6. Rydevik B, Lunborg G, Bagge U, et al. Effects of graded compression on intraneural blood flow: An in vivo study on rabbit tibial nerve.J Hand Surg I98I; 6:3-II.

7. Gelberman RH, Rydevik BL, Pess GM, et al. Carpal tunnel syndrome:A scientific basis for clinical care. Clin Orthop 1988; 178:285-295.

8. Dahlin LB, McLean WG. Effects of graded experimental compression on slow and fast axonal transport in rabbit vagus nerve, J Neuro Sci 1986; 72:19-27.

9. Ditmars DM Jr. Patterns of carpal tunnel syndrome. Hand Clin 1993; 9:241-248.

10. Choi SJ, Ahn DS. Correlation of clinical history and electrodiagnostic abnormalities with outcome after surgery for carpal tunnel syndrome. Plast Reconstr Surg 1998: 102; 2374-2379.

II. Phalen GS. The carpal tunnel syndrome: clinical evaluation of 598 hands. Clin Orthop 1972: 83; 29-35. 
12. Nathan PA, Meadows KD, Doyle LS. Occupation as a risk factor for impaired sensory conduction of the median nerve at the carpal tunnel. J Hand Surg 1988: I3B; 167-172.

13. Dekel S, Papaioannou T, Rushworth G, et al. Idiopathic carpal tunnel syndrome caused by carpal stenosis. $\mathrm{Br}$ Med J 1980: 280; 1297-1302.

14. Gunnarsson LG, Amilon A, Hellstrand P, et al. The diagnosis of carpal tunnel syndrome; sensitivity and specificity of some clinical and electrophysiological tests. J Hand Surg 1997: 22B:I; 34-37.

15. Gerr F, Letz R. The sensitivity and specificity of tests for carpal tunnel syndrome vary with the comparison subjects. J Hand Surg 1998: 23B; I5 I- I55.

16. Yates SK, Hurst LN, Brown WF. Physiological observations in the median nerve during carpal tunnel surgery. Ann Neurol 198I: 10; 227-229.
17. DeKrom MCTFM, Khipschild PG, Kester ADM, et al. Efficacy of provocative tests for diagnosis of carpal tunnel syndrome. Lancet North Am Ed 1990: 335; $393-$ 395.

18. Martinez AC. Diagnostic yield of different electrophysiological methods in carpal tunnel syndrome. Muscle Nerve 1991: 14; 183-189.

19. Muhlau G, Both R, Kunath H. Carpal tunnel syndrome. Course and prognosis.J Neurol 1984: 231; 83-86.

20. DeStefano F, Nordstrom DL, Vierkant RA. Long-term symptoms outcomes of carpal tunnel syndrome and its treatment. J Hand Surg 1997: 22A; 200-2 10. 